\title{
Steam Gasification of Miscanthus Derived Char: The Reaction Kinetics and Reactivity with Correlation to the Material Composition and Microstructure
}

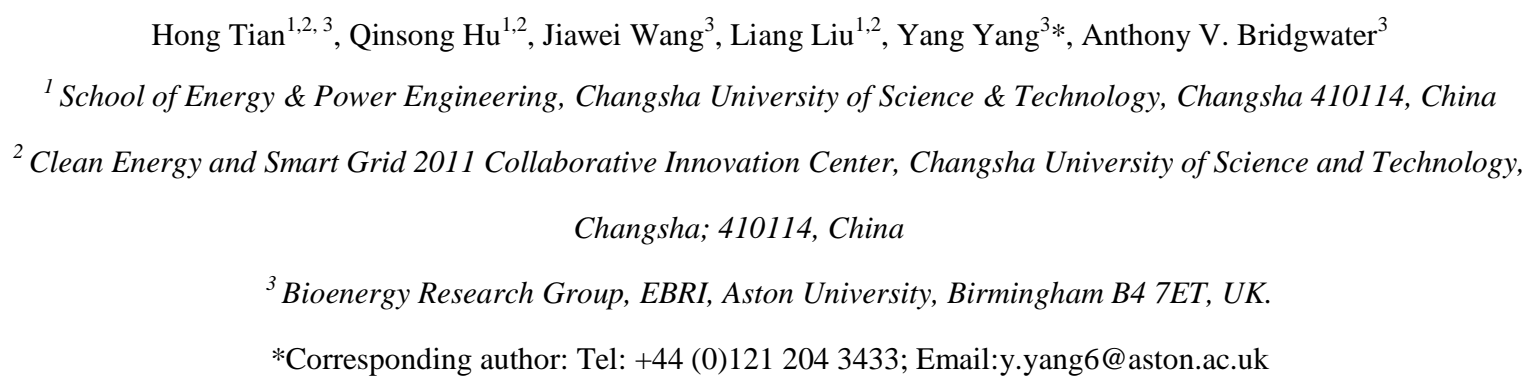

\section{ABSTRACT}

This work presents a comprehensive study on the steam gasification kinetics and reactivity of Miscanthus chars (MC) prepared at different temperatures $\left(600{ }^{\circ} \mathrm{C}, 800{ }^{\circ} \mathrm{C}\right.$ and $\left.1000{ }^{\circ} \mathrm{C}\right)$ with the correlations to their composition and microstructure. The results showed that the order of gasification reactivity was MC600 > MC800 > MC1000, and the microcrystalline structure and the content of inherent alkali and alkaline earth metals in the MC were the main factors affecting their reactivity under steam gasification. The reactivity also increased with the increase of gasification temperature, and the effect of gasification temperature on the reactivity of MC was far greater than that of the char production temperature. High heating rate could also effectively promote the gasification reactivity of MC. The kinetics of the steam gasification process were analyzed by different modelling methods. The Random pore model (RPM), among the three methods compared, was the most suitable one to describe the kinetics of isothermal gasification process, of which, the activation energies were in the range of 176-203 kJ/mol with a good kinetic compensation effect between activation energy and pre-exponential factor. The master-plots method proved that the $\mathrm{F}_{2}$ mechanism was suitable for describing the early stage $(X<50 \%)$ of the MC gasification reaction, and the $\mathrm{D}_{1}$ mechanism was suitable to the late stage $(X>50 \%)$ of the MC gasification process. 


\section{Nomenclatures}

$\begin{array}{llll}A & \text { Pre-exponential factor } & S & \text { Gasification characteristic index } \\ \text { CrI } & \text { Crystallinity index } & S_{\mathrm{BET}} & \text { Total surface area } \\ D_{\mathrm{a}} & \text { Average pore diameter } & S_{\text {micro }} & \text { Micropore surface area } \\ d X / d t_{\text {max }} & \text { Maximum value of gasification rate } & T_{\mathrm{i}} & \text { Initial gasification temperature } \\ d X / d t_{\text {mean }} & \text { Mean value of gasification rate } & T_{\mathrm{m}} & \text { Peak conversion rate temperature } \\ d_{002} & \text { Interlayer spacing } & T_{\mathrm{f}} & \text { Final gasification temperature } \\ E & \text { Activation energy } & t_{\mathrm{g}} & \text { Gasification reaction time } \\ f(X) & \text { Mechanism function } & V_{\text {total }} & \text { Total pore volume } \\ L \mathrm{c} & \text { Crystallite height } & V_{\text {micro }} & \text { Micropore volume } \\ r & \text { Gasification rate } & V_{\text {meso }} & \text { Mesopore volume } \\ R_{\mathrm{s}} & \text { Gasificatio reactivity index } & X & \text { Carbon conversion rate } \\ \text { Abbreviations } & & \\ \text { FWO } & \text { Flynn-Wall-Ozawa } & \text { MC } & \text { Miscanthus char } \\ \text { HM } & \text { Hybrid model } & \text { RPM } & \text { Random pore model } \\ \text { KAS } & \text { Kissinger-Akahira-Sunose } & \mathrm{SCM} & \text { Shrinking core model }\end{array}$

\section{INTRODUCTION}

Biomass is the only alternative source of fixed carbon for the manufacture of carbon 
Miscanthus for optimizing its energy application.

A number of previous research works have addressed the advanced thermal

[5] performed details analysis on the liquid products from fast pyrolysis of Miscanthus under different conditions. It was found that fast pyrolysis had a high oil yield and the oil has high potential to be used as a liquid fuel. Yorgun et al.[6] investigated the influence of pyrolysis temperature, heating rate, and particle size on the pyrolysis of Miscanthus. The oil product was carefully analyzed to determine the composition and characteristics. It was observed that the temperature is the most important variable in pyrolysis of Miscanthus. Jayaraman et al.[7] investigated the pyrolysis, combustion, and gasification behaviors of Miscanthus by TGA-MS method. The results showed that the evolution of the gases released was consistent with the weight loss of the samples during the pyrolysis, combustion and gasification processes. Tian et al.[4]studied the co-pyrolysis of Miscanthus with coal at various pyrolysis temperatures and identified the synergistic effects of the coal and biomass blending on the thermal decomposition rate and the quality of gaseous products. At present, most studies have been focused on gas and liquid products characteristics from the thermal conversion of Miscanthus, but there is limited research on the characteristics of Miscanthus char particularly in the view of application as fuel in terms of further thermal conversion. Zhang et al. [8] reported that biomass gasification process occurred in two stages: pyrolysis and char gasification, and the activation energy in the pyrolysis stage was less than that in the char gasification stage. Tong et al. [9] revealed that the gasification of 
char gasification is the decisive step because of its low gasification rate. A good understanding on the thermal conversion characteristics and kinetics parameters is very important, as can provide important parametric data for the reactor design and process development.

Gasification of biomass under with steam has attracted research attentions and a number of research works have shown that the process had great potential for large-scale development [10-12]. This process had strong advantage of making full use of low-grade solid fuels to produce the high economical value and cleaner products [13]. Waheed et al.[14] reported that the steam gasification of biochar is 2-3 times faster than gasification of coal. Mermoud et al. [15].reported that using steam as the gasification can result in the reaction 2-5 times faster than using $\mathrm{CO}_{2}$. It was shown that steam gasification of biochar can effectively remove the condensable volatiles (tar) during the pyrolysis stage, enabling the solid carbon in the char to react with steam to produce a hydrogen-rich product gas[16]. influence on the gasification reaction characteristics of char $[17,18]$. The physicochemical properties of char are affected by the pyrolysis reaction conditions (temperature, carrier gas, heating rate and residence time)[16, 19], the gasification characteristics of char are affected by gasification reaction conditions i.e. processing temperature and heating rate and reaction agent $[20,21]$.Concerning the properties and gasification characteristics of biomass char. Tong et al.[22] studied the gasification of biomass char samples produced at different temperatures. The results showed that the gasification reactivity of char reduced with the 
increase of char production temperature, but increased with the increase of heating rate.

During pyrolysis, the char surface structure was gradually destructed with vanishing of functional groups, and the microcrystalline structure is a decisive factor for the gasification reactivity. Li et al. [17]investigated the influence of biomass type and char production temperature on char composition and carbonaceous structure. The study showed that the gasification reactivity of char decreased with the increase of char production temperature and carbonaceous structure uniformity. Diao et al. [23] studied the effect of temperature on the gasification reactivity of chars. The results indicated that the level of carbonization and the order degree of char structure were enhanced with the increase of char production temperature. The char prepared at $400{ }^{\circ} \mathrm{C}$ had the optimal gasification reactivity and a gasification temperature of over $1000{ }^{\circ} \mathrm{C}$ would hinder the char gasification reactivity. The microcrystalline structure of char had a great influence on the gasification reaction. Wang et al.[24] investigated the gasification characteristics of chars obtained under different conditions. It showed that the gasification reactivity decreased with the increasing of char production temperature, the gasification reactivity of chars was decreased with the increase of ordering degree of carbonaceous structure.

The design and simulation of biomass gasification furnaces are heavily rely on the biomass pyrolysis kinetics parameters and char gasification kinetics parameters. Some mathematical models have been developed to study the kinetic characteristics of char gasification reactions[25]. Le et al.[26] used shrinking core model(SCM) and uniform reaction model (URM) to study the steam gasification kinetics of refuse derived fuel char under different reaction conditions. The results showed that the results of SCM and URM 
were consistent, and the apparent activation energy of char was between $96-162 \mathrm{~kJ} / \mathrm{mol}$.

Ferreira et al. [16] studied the Arrhenius parameters and the reaction model of the steam gasification of biochar derived from elephant grass by the volumetric model (VM), grain

111 model (GM) and the random pore model (RPM). The kinetic analysis showed that steam 112 gasification of biochar, there was a controlling regime change: chemical kinetics in the 113 lower temperature range and diffusional resistance at higher temperatures. Although the 114 non-isothermal gasification is a complex thermal conversion process, and the iso-conversional 115 method could avoid the influence of model function on the results in kinetic calculation process and 116 obtain a more reliable value of activation energy $E$ [27, 28]. Tong et al.[9] used 117 Flynn-Wall-Ozawa (FWO) and Kissinger-Akahira-Sunose (KAS) to analyze the kinetics and 118 mechanism of gasification reaction of pine sawdust char obtained at different temperatures.

119 It was found that the average values of activation energy were calculated by the two 120 methods were close and proved that $F_{2}$ mechanism was applicable to the gasification of 121 chars at lower temperature, whereas $F_{1}$ mechanism was applicable at higher temperature. 122 There was a compensation effect between activation energy and pre-exponential factor. 123 Zhang et al.[8] studied the gasification reaction kinetics of char by FWO and KAS method. 124 Kinetics analysis showed that the activation energy in the pyrolysis stage was less than that 125 in the char gasification stage and the activation energy calculated by the FWO method were 126 higher than those calculated by the KAS method. Considering all the previous works, there was limited research on the steam gasification characteristics of MC, in particular comprehensively correlating the char's composition, microstructure and its gasification kinetics. The steam gasification reactivity 
130 of char is not well understood. In order to study the reactivity of MC steam gasification, it

131 is necessary to clarify the factors that affect the gasification reactivity of MC firstly and 132 analyze the gasification reaction mechanism. At present, it is still unclear on how the char 133 production temperature affects the physicochemical characteristics of MC, as well as the 134 possibility for the directional control of the MC gasification reactivity by adjusting the 135 reaction conditions. In depth studies on these knowledge gaps are in need, in order to 136 explore the fundamental reaction mechanism, improve the process productivity and enhance 137 the product quality.

138 In this work, the effects of char production temperature on the physicochemical 139 characteristics of MC were studied by TGA and kinetic modelling methods. Further analysis 140 was performed to correlate of composition and microstructure of char on the reactivity of 141 MC steam gasification. Meanwhile, the effects of char production temperature, gasification 142 temperature and gasification heating rate on the gasification characteristics of MC were also 143 discussed. Finally, the gasification kinetic parameters were obtained with different methods 144 and based on the master-plots method, the reaction mechanism functions of MC steam 145 gasification were determined.

2. MATERIAL AND METHODS

\subsection{Feedstock and char preparation}

The Miscanthus sample was sourced from a local farm in Changsha, China. The sample

149 was crushed and screened to a size of less than $0.074 \mathrm{~mm}$ and dried at $105^{\circ} \mathrm{C}$ for 6 hours 150 before use. 
152 prepare the MC samples. A crucible containing $2.5 \mathrm{~g}$ Miscanthus sample was placed in a

153 quartz tube inside the furnace. $\mathrm{N}_{2}(99.999 \%, 50 \mathrm{~mL} / \mathrm{min})$ was used to purge for 30 minutes

154 to eliminate the air from the reactor before the start of heating. After that, the furnace was

155 heated to set point temperatures (i.e. 600,800 and $1000{ }^{\circ} \mathrm{C}$ ) at a constant heating rate of

$15610{ }^{\circ} \mathrm{C} / \mathrm{min}$. The final temperatures were maintained for 1 hour to ensure the conversion was

157 complete. After each pyrolysis run, the cooled chars (MC samples) were collected, weighed,

158 and then stored in sealed sample bags for further experiment. The char produced at 600,800

159 and $1000{ }^{\circ} \mathrm{C}$ were labelled as MC600, MC800 and MC1000, respectively. The results of

160 proximate analysis and ultimate analysis are shown in Table 1.

Table1 Proximate and ultimate analysis results of samples

\begin{tabular}{|c|c|c|c|c|c|c|c|c|c|c|c|}
\hline \multirow{2}{*}{ Samples } & \multicolumn{3}{|c|}{ Proximate analysis ${ }^{\mathrm{a}}(\mathrm{wt}, \%)$} & \multicolumn{4}{|c|}{ Ultimate analysis $^{\mathrm{b}}(\mathrm{wt}, \%)$} & \multirow{2}{*}{$\mathrm{H} / \mathrm{C}$} & \multirow{2}{*}{$\mathrm{O} / \mathrm{C}$} & \multirow{2}{*}{$\begin{array}{c}\mathrm{CY}^{\#} \\
(\mathrm{wt} \%)\end{array}$} & \multirow{2}{*}{$\begin{array}{c}\mathrm{HHV}^{\mathrm{c}} \\
(\mathrm{MJ} / \mathrm{kg})\end{array}$} \\
\hline & Ash & Volatile & Fixed carbon & $\mathrm{C}$ & $\mathrm{H}$ & $\mathrm{O}^{*}$ & $\mathrm{~N}$ & & & & \\
\hline Miscanthus & 3.51 & 74.84 & 21.65 & 50.93 & 7.14 & 41.56 & 0.27 & 1.68 & 0.61 & - & 20.33 \\
\hline MC600 & 12.18 & 15.27 & 72.55 & 92.90 & 2.41 & 3.81 & 0.63 & 0.31 & 0.03 & 25.53 & 30.24 \\
\hline MC800 & 12.28 & 8.79 & 78.93 & 92.49 & 1.59 & 5.22 & 0.55 & 0.21 & 0.04 & 22.59 & 28.95 \\
\hline MC1000 & 12.99 & 8.04 & 78.97 & 91.74 & 2.20 & 5.41 & 0.31 & 0.29 & 0.04 & 20.62 & 29.36 \\
\hline
\end{tabular}

${ }^{\mathrm{a}}$ Air Dried basis. ${ }^{\mathrm{b}}$ Dry and ash-free basis. ${ }^{\mathrm{c}}$ Higher heating value on dry basis. *calculated by difference. ${ }^{\#}$ Char yield.

\subsection{Structural characterization of char}

For char characterization and analysis, the surface morphology of the chars were analyzed by

SEM (JSM-6060LA) at the conditions of a $20 \mathrm{kV}$ voltage. The pore structure of the chars were

characterized by $\mathrm{N}_{2}$ adsorption at $77 \mathrm{~K}$ using Micromeritics ASAP 2020 nitrogen adsorption

instrument. Specific surface areas were determined by the Brunauer-Emmett-Teller (BET) model,

the pore size distribution was presented following the Barrett-Johner-Halenda (BJH) model [22].

The chemical functional groups of the chars were analyzed using a Nicolet IS10 FTIR Spectrometer 
crystallinity of mineral materials in the chars were characterized by a Rigaku UltimateIVX-ray diffractometer (XRD) using $\mathrm{CuK} \alpha$ radiation $(40 \mathrm{kV}, 40 \mathrm{~mA})$. The curves were recorded from $10^{\circ}$ to $80^{\circ}(2 \theta)$ at $2 \% \mathrm{~min}$. The element composition and relative content on the surface of chars by X-ray photoelectron spectroscopy (XPS) (Themo Scientific K- $\alpha+$ ). Using an AlK $\alpha$ monochromatic ray light source with a beam spot of $400 \mu \mathrm{m}$. The survey scan spectra were collected in the $1400 \mathrm{eV}$ binding energy range in $1 \mathrm{eV}$ steps with a pass energy of $100 \mathrm{eV}$, high resolution scanning of the $\mathrm{C} 1 \mathrm{~s}$ and Ols region was also conducted in $0.1 \mathrm{eV}$ steps with a pass energy of $50 \mathrm{eV}$ [29].

\subsection{Gasification experiment}

A NETZSCH STA449F3 thermogravimetric analyzer (TGA) was used to carry out the char steam gasification experiment, from which the results were used to calculate the kinetic parameters of char gasification. The quantity of each sample was maintained to $10 \pm 0.5 \mathrm{mg}$. High purity nitrogen $(99.999 \%, 20 \mathrm{ml} / \mathrm{min})$ was used as the carrier gas. For the isothermal gasification experiments, the sample was heated from room temperature to $105^{\circ} \mathrm{C}$ with a heating rate of $20{ }^{\circ} \mathrm{C}$ /min. This temperature was held for 15 minutes to ensure the samples were completely dry. After this, the sample was heated to the set gasification temperatures (i.e. $800{ }^{\circ} \mathrm{C}, 900{ }^{\circ} \mathrm{C}$, and $1000{ }^{\circ} \mathrm{C}$ ) with a heating rate of $20{ }^{\circ} \mathrm{C} / \mathrm{min}$. As soon as the samples reached the final temperature, nitrogen was replaced by steam (with a flow rate of $100 \mathrm{ml} / \mathrm{min}$ ). The gasification temperature was maintained until the gasification reaction complete. For the non-isothermal gasification experiment, the sample was heated from room temperature to $105^{\circ} \mathrm{C}$ with heating rates of 5,10 or $20{ }^{\circ} \mathrm{C} / \mathrm{min}$ with nitrogen flow. After the drying stage, nitrogen was replaced by steam, which entered the TGA chamber through a heat preservation pipeline with a flowrate of $100 \mathrm{ml} / \mathrm{min}$. Upon the steam flow stabilized, the samples were heated to $1000{ }^{\circ} \mathrm{C}$ with a heating rate of $20{ }^{\circ} \mathrm{C} / \mathrm{min}$. 


\subsection{Characterization of char steam gasification}

The calculation for carbon conversion rate $X(\%)$ and gasification rate $r(\% / \mathrm{min})$ were expressed as [22].

$$
\begin{gathered}
X=\frac{W_{0}-W_{t}}{W_{0}-W_{a s h}} \\
r=\frac{d X}{d t}
\end{gathered}
$$

where $W_{0}$ is the initial weight $(\mathrm{mg}), W_{\mathrm{t}}$ is the instantaneous weight $(\mathrm{mg})$ at a gasification reaction time $t(\mathrm{~min})$, and $W_{\text {ash }}$ is the mass of ash (mg). A high $r$ value indicated that the better gasification reactivity.

The quantitative description of reactivity index $R_{\mathrm{s}}\left(\mathrm{min}^{-1}\right)$ is beneficial to compare the isothermal gasification reactivity of different biomass chars. A high $R_{\mathrm{S}}$ value indicated that the shorter time required for carbon conversion rate of char gasification to reach $50 \%$. The equation is as follows:

$$
R_{s}=\frac{0.5}{\tau_{0.5}}
$$

Where $\tau_{0.5}$ indicates the time required for carbon conversion rate of $50 \%(\mathrm{~min})$.

In order to clearly analyze the effect of heating rate on the steam gasification reactivity of char. The quantitative description of the gasification reactivity by comprehensive gasification characteristic index $S$. A higher $S$ value indicated a high gasification reactivity of char. Simultaneously parameters of $T_{\mathrm{i}}, T_{\mathrm{m}}, T_{\mathrm{f}}$ and $t_{\mathrm{g}}$ were proposed to evaluate the gasification process of different samples [22]. 


$$
S=\frac{(d X / d t)_{\max } \cdot(d X / d t)_{\text {mean }}}{T_{i}^{2} \cdot T_{f}}
$$

213 where $(\mathrm{d} X / \mathrm{d} t)_{\max }$ is the maximum value of gasification rate $(\% / \mathrm{min}),(\mathrm{d} X / \mathrm{d} t)_{\text {mean }}$ is the mean value

214 of gasification rate $(\% / \mathrm{min}) . T_{\mathrm{i}}, T_{\mathrm{m}}, T_{\mathrm{f}}$ and $t_{\mathrm{g}}$ represented the initial gasification temperature $\left({ }^{\circ} \mathrm{C}\right)$,

215 peak conversion rate temperature $\left({ }^{\circ} \mathrm{C}\right)$, final gasification temperature $\left({ }^{\circ} \mathrm{C}\right)$, and the time from

216 beginning to end of the gasification reaction (min), respectively.

\subsection{Kinetic model description}

Kinetic model can predict the complex reaction process and mechanism by a series of thermogravimetric data. It is known that gasification of char is a gas-solid non catalytic heterogeneous reaction and the gasification reaction rate can be expressed as following:

$$
\frac{d X}{d t}=k \cdot f(X)
$$

where $k$ represents the reaction rate constant, according to the Arrhenius law, $k=A \cdot \exp (E / R T)$. $A$ is constant, $8.314 \mathrm{~J} /(\mathrm{mol} \cdot \mathrm{K}) \cdot f(X)$ is the reaction kinetics which depends on the reaction mechanism, $f(X)=(1-X)^{\mathrm{n}}, n$ is reaction order.

In this study, three models were used in order to assessing the gasification kinetics of biochar and hybrid model (HM)[30, 21, 31]. The RPM model takes into account the pore structure and its evolution during the course of reaction. The SCM model assumes that the reaction starts from the particle surface and forms a gray layer. The unreacted core shrinks with the increase of the reaction time, but the gasifier always reacts on the outer surface of the unreacted core and does not penetrate 233 into the core. The hybrid model (HM) combines the two cases of homogeneous model and 
shrinking core model, considering both empirical factors and the significance of some physical parameters. The gasification rate can be calculated as:

$$
\frac{d X}{d t}=k_{S C M}(1-X)^{2 / 3}
$$

$$
\frac{d X}{d t}=k_{H M}(1-X)^{n}
$$

where $k_{\mathrm{RPM}}, k_{\mathrm{SCM}}$ and $k_{\mathrm{HM}}$ denote the RPM, SCM and $\mathrm{HM}$ reaction rate constant respectively. $\varphi$ is a structural constant[16].

According to Eq.5, the constant heating rate $\beta=d T / d t\left({ }^{\circ} \mathrm{C} / \mathrm{min}\right)$ is connected in non-isothermal experiments [32].

$$
\frac{d X}{d t}=\frac{A}{\beta} \exp \left(-\frac{E}{R T}\right) f(X)
$$
activation energy values are very reliable [33] .

$$
\ln (\beta)=\ln \left(\frac{A E}{R G(X)}\right)-5.331-1.052 \frac{E}{R T}
$$

at each given $X$, the value of $E$ is determined from the slope of a plot of $\ln (\beta), \ln \left(\beta / T^{2}\right), \ln \left(\beta / T^{1.92}\right)$ 

analysis kinetic equation integral can be expressed as follows[34]:

$$
\begin{gathered}
G(X)=\int_{0}^{X} \frac{d X}{f(X)}=\frac{A}{\beta} \int_{T_{0}}^{T} \mathrm{e} \times\left(-\frac{E}{R T}\right) d T=\frac{A E}{\beta R}\left[P(U)-P\left(U_{0}\right)\right] \cong \frac{A E}{\beta R} P(U) \\
P(U)=\frac{\exp (-1.0008 U-0.312)}{U^{1.92}} \\
\frac{P(U)}{P\left(U_{0} . \$\right.}=\frac{\Phi \not X}{\left.\Phi X_{0}\right)} .
\end{gathered}
$$

where $P(U)$ is temperature integral; $G\left(X_{0.5}\right), P\left(U_{0.5}\right)$ are the value of $G(X)$ and $P(U)$ when $X=50 \%$; $U=E / R T ; U_{0.5}=E / R T_{0.5} ; T_{0.5}$ is the temperature at $X=50 \%$. Through various most commonly used the integrated form of the reaction function $G(X), G(X) / G\left(X_{0.5}\right) \sim X$ can be plotted to obtain the theoretical curve. Simultaneously use the calculated average value of $E$ and the temperature $T$ value at different $X$ to find $P(U)$. The experimental curve can be obtained through the relationship of $P(U) / P\left(U_{0.5}\right) \sim X$. Eq.15 shows that for a given $X$, the experimental value of $P(U) / P\left(U_{0.5}\right)$ is consistent with the theoretical value of $G(X) / G\left(X_{0.5}\right)$ when a suitable kinetic model is used. At this time, the mechanism function corresponding to the theoretical curve that best matches the experimental curve is the most probable mechanism function of the char gasification. The kinetic model function $G(X)$ corresponding to the theoretical curve is considered to be kinetic of the experimental curve.

\section{RESULTS AND DISCUSSION}

\subsection{Characterization of MC samples}

\subsubsection{SEM and pore structure analysis}

Fig.1 shows the SEM results of raw Miscanthus and three char samples. The Miscanthus 
sample showed a rod-shaped structure with relatively smooth surface. With the increase of char

production temperature, although the surface of char samples remained the similar structure, it began to show increasing bulges and cracks. High char production temperature caused deepened surface structure, high surface roughness and increased surface pores leading to collapsed large holes. It can be clearly seen that for MC600, the precipitation of volatiles during the heating process resulted in structure bubbles merged into pore on the char surface. For MC800 the pore structure was deepened and surface crack began to increase, leading to the carbonaceous structure gradually destroyed. For MC1000 the char structure was further fractured with more and more cracks, the carbon skeleton was destroyed. The phenomenon of melting collapse was also observed, which was caused by the melting of the crystal cell structure [35].
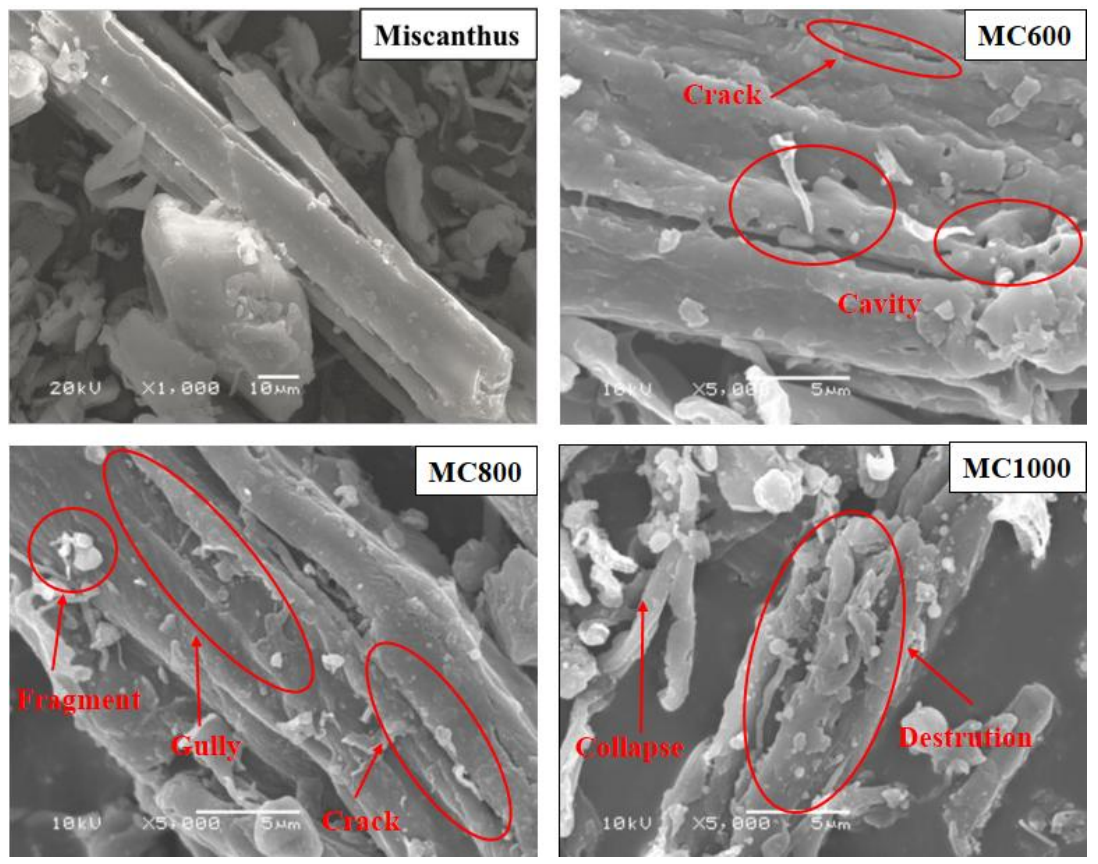

Fig.1 Surface morphology of Miscanthus and MC samples

Fig.2a shows the $\mathrm{N}_{2}$ adsorption and desorption isotherms of the chars. It can be seen that when

the relative pressure was less than 0.1 , the gas adsorption capacity increased dramatically, which indicated a strong interaction between char and $\mathrm{N}_{2}$ as well as a large number of microspores. When 
the relative pressure was increased from 0.4 to 0.8 , the adsorption capacity increased slightly, indicating possible increasing amount of large sizes mesopores in char. Meanwhile, the curves appeared hysteresis due to the capillary condensation in the mesopore, especially the hysteresis cycle of MC800 and MC1000 was the most apparent[22]. According to the International Union of Pure and Applied Chemistry (IUPAC) classification, all biomass chars have type IV isotherms with H4 hysteresis loop, resulting from slit-like pores, which indicates biomass chars have rich mesoporous[22]. In addition, it can be found that as the char production temperature increased, the adsorption capacity increased. This indicated that a better pore structure was developed at high temperature. Fig. $2 \mathrm{~b}$ shows the pore size distribution of different char samples. According to IUPAC, pore size was divided into three categories: i.e. micropore $(<2 \mathrm{~nm})$, mesopore $(2-50 \mathrm{~nm})$, and macropore $(>50 \mathrm{~nm})$ [36]. It was shown from Fig. $2 \mathrm{~b}$ that peaks of pore diameter shift considerably with the change of char production temperature. All the three curves showed intensive peaks between 0.25 and $1.5 \mathrm{~nm}$, indicating the presence of microporous. However, the MC1000 also showed peaks from $2.3 \mathrm{~nm}$, indicating the presence of mesoporous structures. The experimental results also showed that high char production temperature makes the increase of pore diameter, the quantity of micro- and mesoporous in the char increased with the increase of char production temperature. 

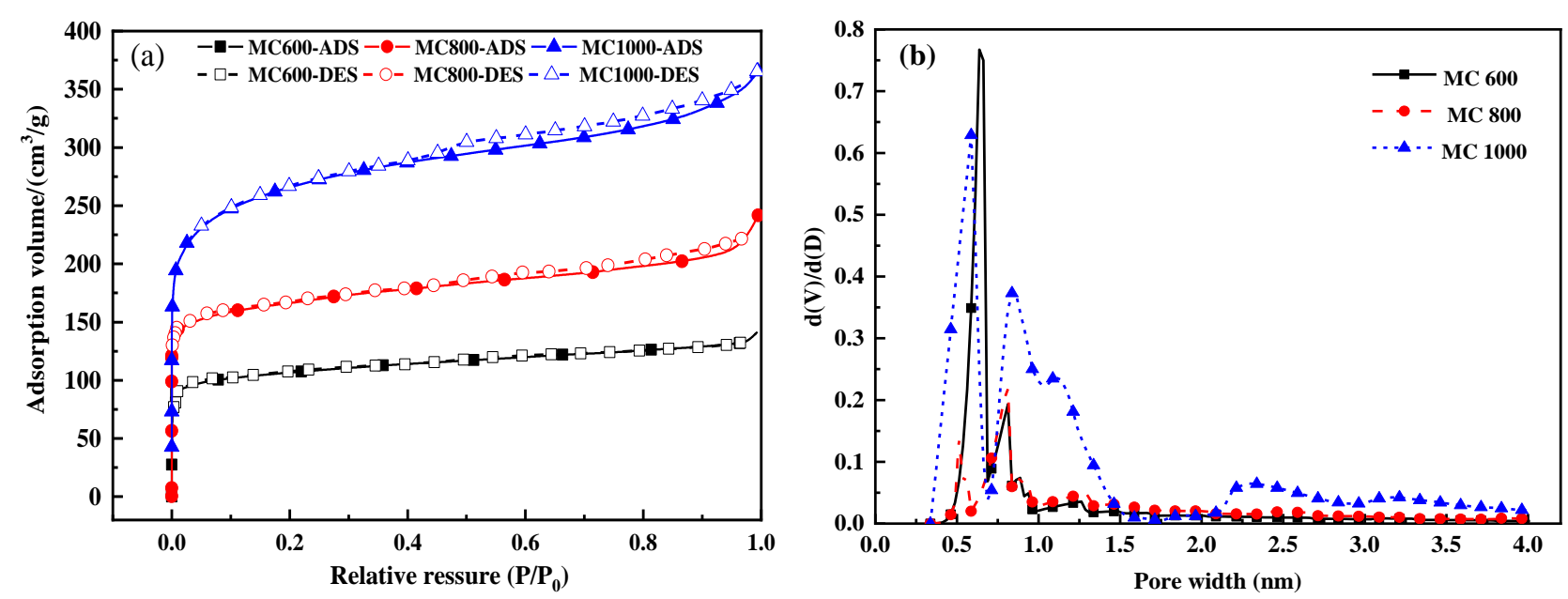

Fig.2 Analysis of pore structure of MC samples. (a) $\mathrm{N}_{2}$ adsorption isotherms; (b) Pore size distribution.

Table 2 shows the structural parameters of different char samples according to the $\mathrm{N}_{2}$ adsorption tests. It can be found that the total surface area $\left(S_{\mathrm{BET}}\right)$, micropore surface area $\left(S_{\text {micro }}\right)$ and micropore $\left(V_{\text {micro }}\right)$, mesopore $\left(V_{\text {meso }}\right)$, and total pore volume $\left(V_{\text {total }}\right)$ all increased with the increase of char production temperature, mainly due to the precipitation of volatiles at high temperatures and the release of tar in the crosslinked skeleton during heat treatment. The ratio of micropore volume

313 to total pore volume $\left(V_{\text {micro }} / V_{\text {total }}\right)$ decreased with the increase of char production temperature.

314 Compared to MC600, the $V_{\text {micro }}$ of MC800 and MC1000 increased by 1.54 and 1.79 times, 315 respectively, and the $V_{\text {meso }}$ increased by 2.69 and 8.07 times, respectively. At this time, the increase 316 of mesoporous is higher than that of micropores, resulting in a decrease in $V_{\text {micro }} / V_{\text {total. }}$ The average 317 pore diameter $\left(D_{\mathrm{a}}\right)$ raised first and then decreased as the char production temperature increased. The 318 reason is that very high temperature could cause the carbon skeleton structure to collapse, as shown 319 in the Fig. 1.

Table 2 structural parameters of MC samples

\begin{tabular}{cccccccc}
\hline Samples & $S_{\mathrm{BET}}\left(\mathrm{m}^{2} / \mathrm{g}\right)$ & $S_{\text {micro }}\left(\mathrm{m}^{2} / \mathrm{g}\right)$ & $V_{\text {total }}\left(\mathrm{cm}^{3} / \mathrm{g}\right)$ & $V_{\text {micro }}\left(\mathrm{cm}^{3} / \mathrm{g}\right)$ & $V_{\text {meso }}\left(\mathrm{cm}^{3} / \mathrm{g}\right)$ & $V_{\text {micro }} / V_{\text {total }}$ & $D_{\text {a }}(\mathrm{nm})$ \\
\hline MC600 & 403.46 & 259.82 & 0.2163 & 0.1876 & 0.0287 & 0.8673 & 2.1442 \\
MC800 & 629.32 & 476.74 & 0.3666 & 0.2895 & 0.0771 & 0.7897 & 2.3300
\end{tabular}




$\begin{array}{llllllll}\text { MC1000 } & 981.75 & 788.17 & 0.5665 & 0.3350 & 0.2315 & 0.5914 & 2.3082\end{array}$

\subsubsection{FTIR analysis}

Fig. 3 shows the FTIR analysis on the surface functional groups of different char samples. The hydroxyl peak at $3440 \mathrm{~cm}^{-1}$ attributed to the $-\mathrm{OH}$ stretching vibration of alcohols, phenols, and carboxylic acids in chars. The peak at $2920 \mathrm{~cm}^{-1}$ attributed to the asymmetric tensile vibration of aliphatic $\mathrm{CHx}$. The peak at $1630 \mathrm{~cm}^{-1}$ attributed to the conjugated $\mathrm{C}=\mathrm{C}$ stretching vibration. The peak at $1410 \mathrm{~cm}^{-1}$ attributed to the fatty chain $\mathrm{CH}_{3^{-}}, \mathrm{CH}_{2^{-}}$. The peak at $1100 \mathrm{~cm}^{-1}$ was attributed to the aromatic ring tensile vibration or C-O tensile vibration. And the peak at $880 \mathrm{~cm}^{-1}$ attributed to the $\mathrm{C}-\mathrm{H}$ vibration of the aromatic nucleus. functional groups in char reduced, and some even disappeared in the MC1000. With the char production temperature rising, the strength of the $-\mathrm{OH}$ absorption peak at $3440 \mathrm{~cm}^{-1}$ decreased, but the peak intensity was still relatively high, which was mainly caused by the -OH stretching of water in char[37, 38]. At $2920 \mathrm{~cm}^{-1}$, the absorption peak caused by aliphatic C-H stretching gradually disappeared. It was due to the decomposition of some aliphatic hydrocarbons and the opening of the alkyl chains during pyrolysis[39]. For MC1000, the peaks at $1750-1200 \mathrm{~cm}^{-1}$ disappeared. In contrast, the peaks related to the benzene ring C-H vibration below $1200 \mathrm{~cm}^{-1}$ still presented, which indicated that all of the ketones, aldehydes, carboxylic acids, and $\mathrm{R}-\mathrm{CH}_{3}, \mathrm{R}^{\prime}-\mathrm{CH}_{2}-\mathrm{R}$ groups vanished, and the structure of the char became aromatic. The char prepared at high temperature was aromatic with highly ordered structure. Therefore, it can be inferred that as the char production temperature increases, the most of the functional groups in chars were gradually diminished and most of the 
oxygen containing groups (e.g.C=O) were eliminated. The char samples prepared at higher temperatures tend to have a more stable structure and therefore is more difficult to be decomposed.

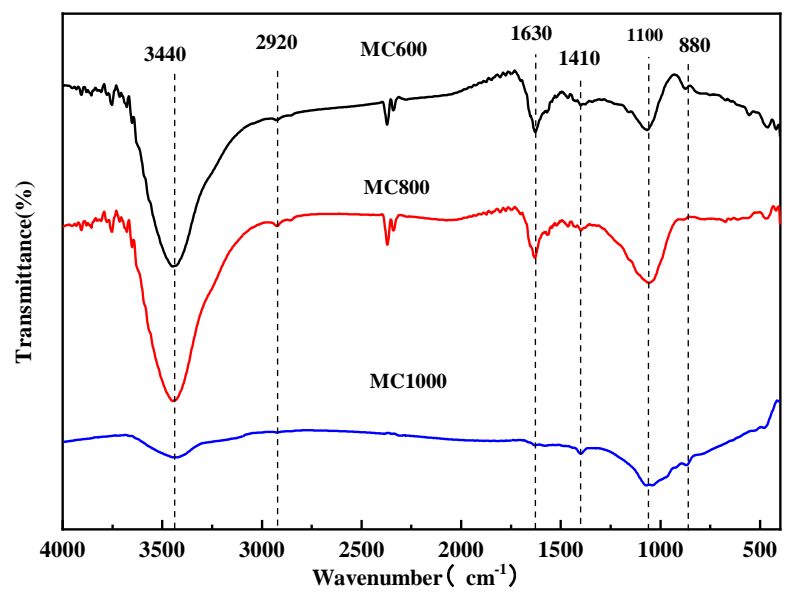

Fig.3 FTIR spectrum of MC samples

\subsubsection{XRD analysis}

Fig.4 shows the diffraction curves of the char samples. There are two distinct diffraction peaks in the XRD pattern. The tall and slim (002) peak indicated the regular arrangement of the carbon structure with a high the degree of order. It was found that as the char production temperature increased, the (002) peak became taller and slimmer. The $2 \theta$ value of the sharp peak at $20-30^{\circ}$ indicates the existence of graphene-like structure in char[40] and the formation of aromatic carbon compounds [41]. Based on the Bragg and Scherer equations, the stack up structure parameters of aromatic layers such as interlayer spacing $d_{002}$, crystallite height $L c$, could be calculated by means of wave peak and diffraction angle. With the increase of char production temperature, the value of $d_{002}$ decreased from 0.4138 to $0.4050 \mathrm{~nm}$ and the $L \mathrm{c}$ increased from 0.3658 to $0.5385 \mathrm{~nm}$, which indicates that the aromatic layer was more close and sturdy degree of stacking and the arrangement of microcrystalline is more regular and orderly [9]. The crystallinity index CrI of the MC600, 
a high degree of graphitization and stability in structure leading to potential low reactivity.

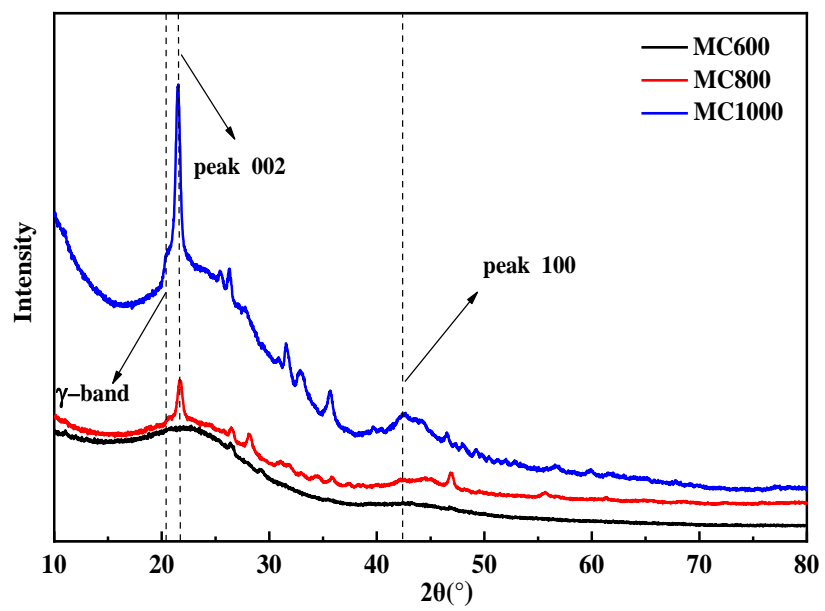

Fig.4 X-ray diffraction patterns of MC samples

\subsubsection{XPS analysis}

Table 3 shows the results from XPS analysis on chemical properties of elements and functional groups on the surface of char samples. The main elements on the surface of char are $\mathrm{C}$ and $\mathrm{O}$ with trace amounts of $\mathrm{K}$ and $\mathrm{Ca}$. As the char production temperature increased, the $\mathrm{C}$ content in the char samples increased, but those of $\mathrm{O}$ and $\mathrm{K}$ reduced. During the pyrolysis of biomass (char production), K release amount increased significantly with the increase of char production temperature, and the $\mathrm{K}$ entered the gas phase as $\mathrm{KCl}$ and $\mathrm{KOH}$ at high-temperature, which made the content of $\mathrm{K}$ decreased in the solid phase product [42-45]. With the increase of char production temperature, the trend of $\mathrm{Ca}$ content increased first and then decreased. The main reason is that $\mathrm{Ca}$ is an active divalent metal, which can rapidly combine with carbon and remain in char in the form of oxides and inorganic salts (e.g sulfate, silicate and aluminosilicate). This made $\mathrm{Ca}$ was hardly released at modest temperature. While the volatile matter being released during pyrolysis, the Ca content was proportionally increased in the solid product[46]. As the char production temperature raised above $850{ }^{\circ} \mathrm{C}, \mathrm{Ca}$ and other metal ash and compounds started melting [45]. The behavior of Ca largely depends on their secondary transformations both inside and over char particles, some calcium 
compounds in the char was decomposed after melting and joined the volatile to become part of the vapor phase product. This resulted in the content of $\mathrm{Ca}$ in the char decreased[47]. It is well known that the alkali and alkaline earth metals are the catalytic active sites of biomass char. $\mathrm{K}$ and $\mathrm{Ca}$ in char have a catalytic effect on the primary devolatilisation and secondary cracking, which can reduce the activation energy and increase the gas product yields. In addition, they can also play a noticeable role in inhibiting char graphitization and vapor/tar condensation during the gasification process [48]. The mass ratio of $\mathrm{O} / \mathrm{C}$ decreased with the increase of char production temperature, which indicated that enrichment of samples for carbon which makes the sample prepared at higher temperatures more suitable for activated carbon production [29]. H cannot be detected by XPS, and based elemental analysis.

Table 3 Surface element and functional group analysis of MC samples

\begin{tabular}{cccccccccccc}
\hline \multirow{3}{*}{ Smples } & \multicolumn{4}{c}{ Surface element ratio (\%) } & \multicolumn{7}{c}{ Function group ratio (\%) } \\
\cline { 2 - 11 } & C & O & K & Ca & O/C & C-C & C-H & C-O & C=O & O=C-O \\
\hline MC600 & 84.76 & 13.64 & 0.56 & 1.04 & 0.12 & 32.17 & 47.00 & 24.90 & 58.78 & 16.33 \\
MC800 & 89.67 & 8.62 & 0.45 & 1.27 & 0.07 & 24.97 & 48.25 & 21.90 & 25.55 & 52.55 \\
MC1000 & 91.88 & 7.43 & 0.13 & 0.56 & 0.06 & 22.16 & 47.01 & 6.82 & 24.99 & 68.19 \\
\hline
\end{tabular}

Fig. 5 shows the Cls and Ols spectra of three char samples and their curve fitting. From the 391 results of peak segmentation, it can be seen that the Cls and Ols spectra of the three chars can be 392 divided into five categories: C-C related to graphite carbon, C-H related to hydrocarbons, C-O 393 related to phenolic alcohol ether, $\mathrm{C}=\mathrm{O}$ related to the carbonyl group and $\mathrm{O}=\mathrm{C}=\mathrm{O}$ related to the 394 carboxyl group or ester. As can be seen from Table 3, for Cls, the main functional groups are C-C 
and $\mathrm{C}-\mathrm{H}$. With the increase of char production temperature, the carbon structure of char was destructed, leading to the reduction of $\mathrm{C}-\mathrm{C}$ ratio. The increase first and then decrease of hydrocarbon $\mathrm{C}-\mathrm{H}$ content indicates that the tar fraction adsorbed on the surface of carbon-matrix is significantly thermally decomposed and reformed under pyrolysis process to expose more unsaturated $\mathrm{C}$ elements, and with the $\mathrm{H}$ radicals to form hydrocarbon $\mathrm{C}-\mathrm{H}$, but the $\mathrm{C}-\mathrm{H}$ was consumed again with the temperature rising [49]. For Ols, the main functional groups were C-O, $\mathrm{C}=\mathrm{O}$ and $\mathrm{O}=\mathrm{C}-\mathrm{O}$. As the char production temperature increased, the ratio of $\mathrm{C}-\mathrm{O}$ and $\mathrm{C}=\mathrm{O}$ decreased, while the ratio of $\mathrm{O}=\mathrm{C}-\mathrm{O}$ increased. $\mathrm{C}-\mathrm{O}$ was considered to be the most important oxygen-containing functional group on the surface of char serving as an active site and as a medium for catalyzing the migration of substances from the interior to the gas-solid interface $[49,50]$.
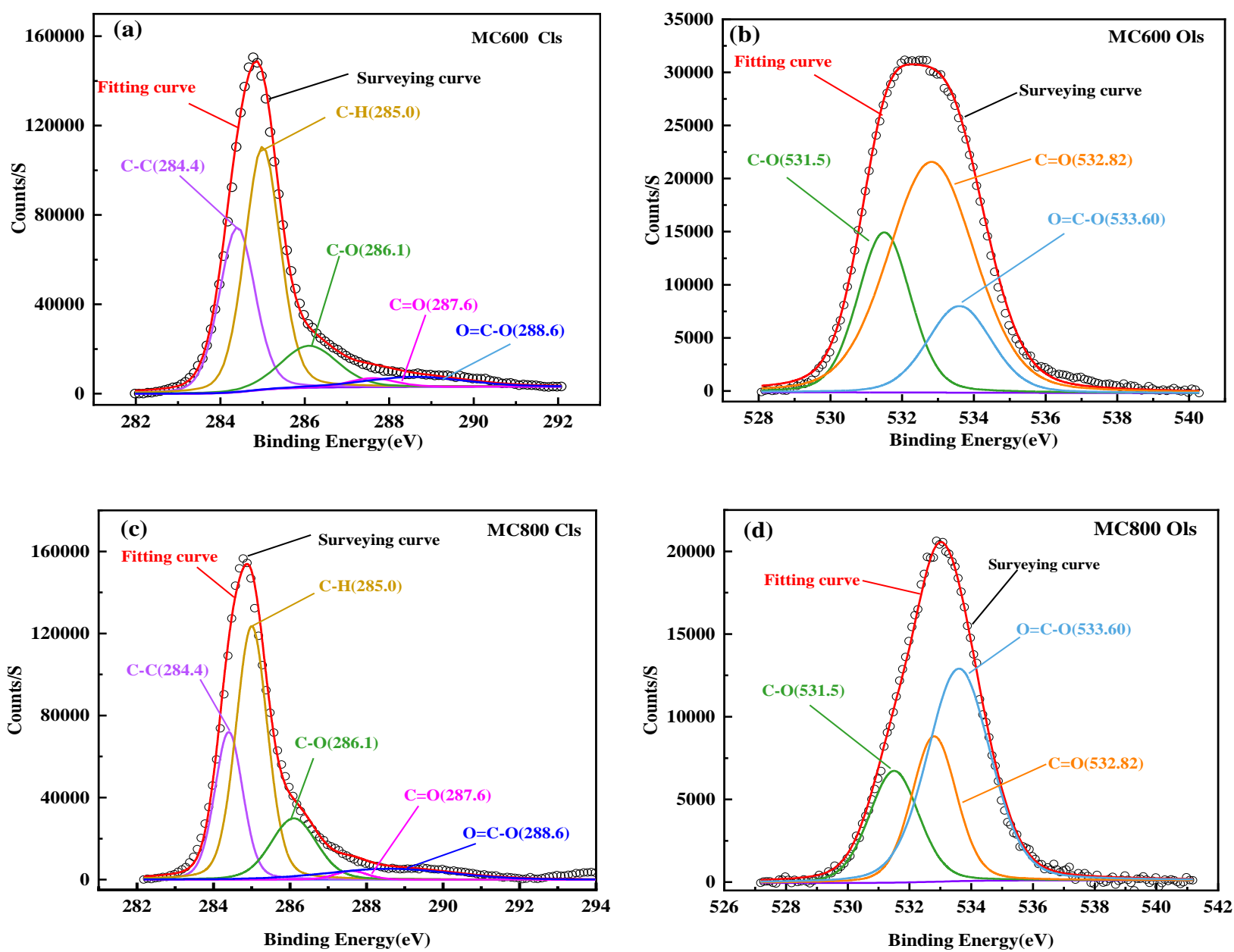

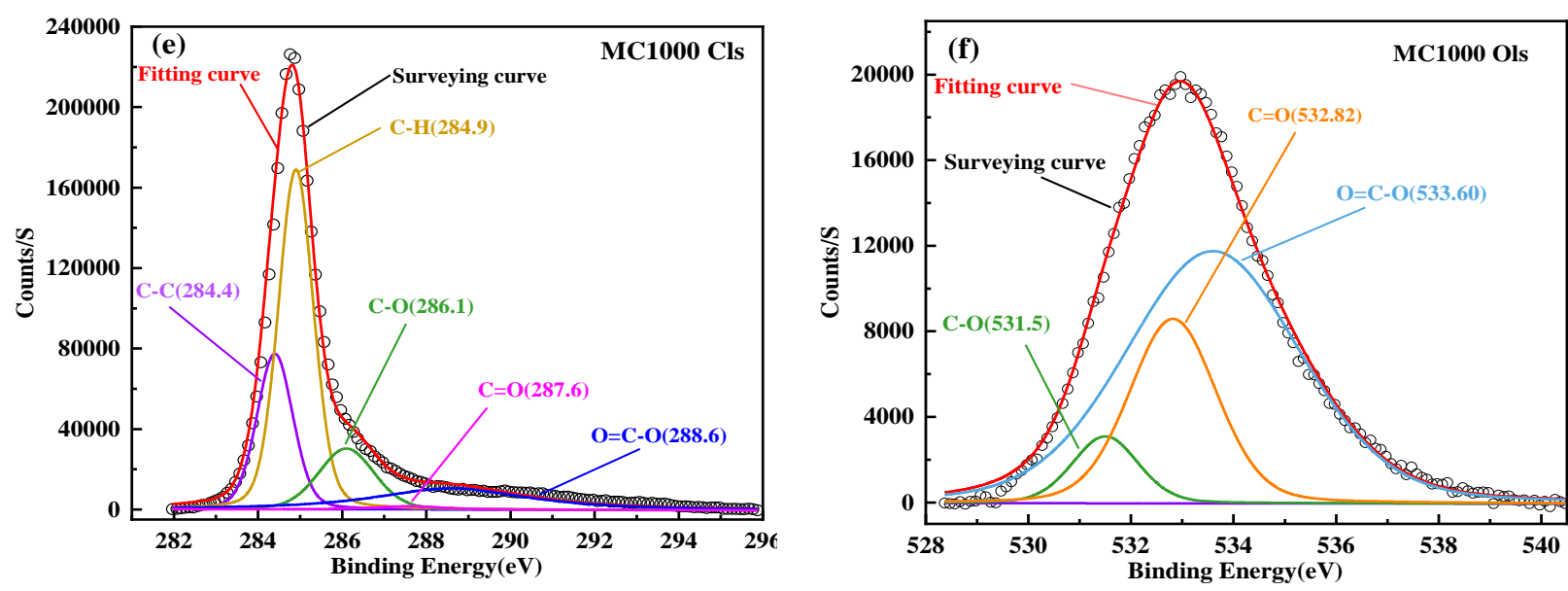

Fig. $5 \mathrm{Cls}$ and Ols peak fitting curves of MC samples

3.2 Isothermal gasification reactivity analysis

\subsubsection{Effect of temperature}

Fig.6 shows the results of steam gasification of three types of char samples at different processing temperatures. It is found from Fig. 6a that at the same gasification temperature, the char samples prepared at high-temperatures (e.g. MC1000) had a relatively low carbon conversion rate

411 and required long reaction time to achieve a full conversion. As discussed in the XRD analysis, this

412 is likely because the char produced at high production temperature has more stable structure with a

413 high degree of graphitization, resulting in low reactivity. In addition, as confirmed by the results

414 from the SEM and XPS analyses, high char production temperature led to the collapse of the char

415 carbon skeleton, and reduction in contents of alkali and alkaline earth metals ( $\mathrm{K}$ and $\mathrm{Ca})$ and in the 416 C-O functional groups, which can serve as active sites for catalytic cracking. These both can lead to

417 reduced char gasification reactivity during high temperature gasification [51]. In addition, it can be 418 observed that, for the char produced at the same temperature, the high gasification temperature 419 resulted in a high carbon conversion rate, shortened conversion time and better gasification reactivity. 
Fig. $6 \mathrm{~b}$ shows the relationship between the char gasification reaction rate and the carbon conversion rate, this result was calculated by Eqs 1 and 2. At the same carbon conversion rate, the gasification reaction rate of char increased significantly with the rise of gasification temperature and decreased with the rise of char production temperature. The corresponding carbon conversion rate when the gasification reaction rate reaches the maximum is related to the gasification temperature.

When the gasification temperature is $800{ }^{\circ} \mathrm{C}$, the gasification rate reaches the maximum at $X=10 \%$, for $1000{ }^{\circ} \mathrm{C}$ the gasification rate reaches the maximum at $X=50 \%$. With the increase of carbon conversion rate, the gasification rate was increasing to reach a peak value and then graduate decreased to zero. In the beginning of the gasification reaction, steam can firstly diffuse to the surface of the char layer and then enter into the interior of the char particles through the porous surface. The generated gases increased the inner pressure inside the char, resulting in char cracking and bursting. During the char expansion, gas-solid interaction was enhanced and eventually led to increased gasification reaction rate. As gasification continues, the pore structure in the char collapsed and pore cross-linking occurred, resulting in less specific surface area available for of the increased but decreased with the rise of carbon conversion.
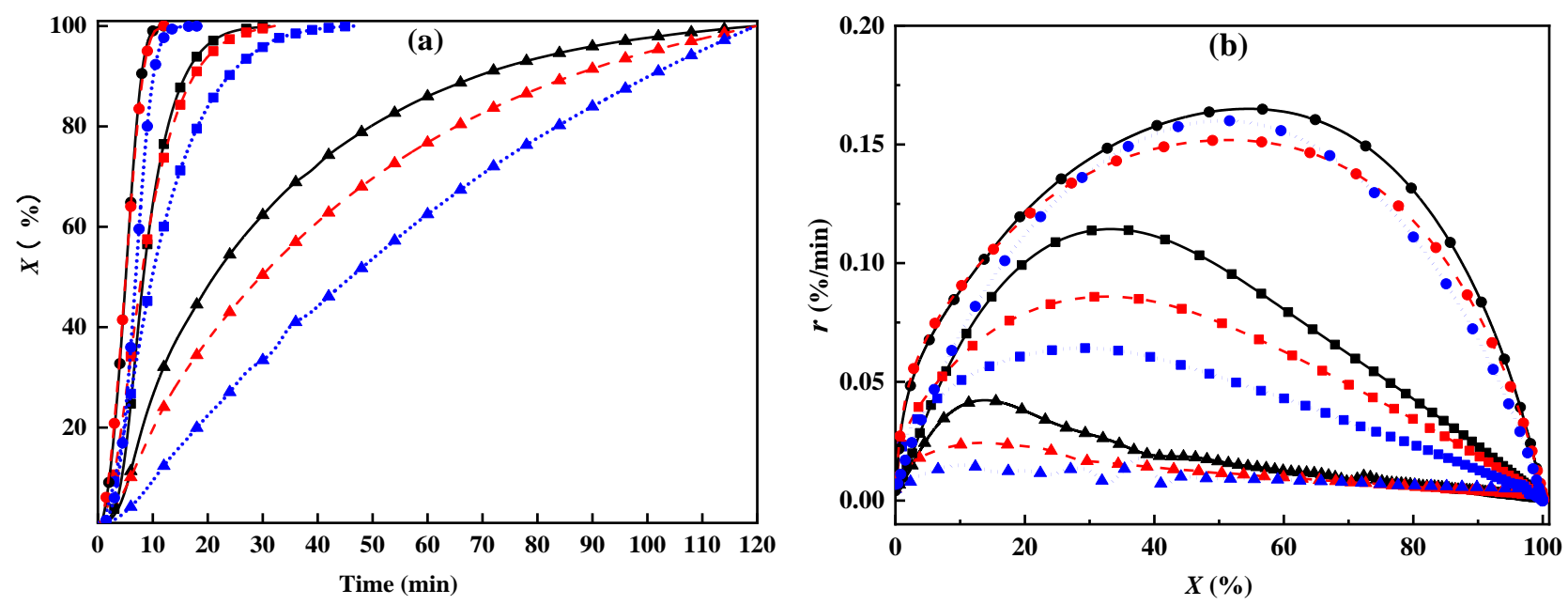
439 Fig. 6 Steam gasification characteristics of MC samples at different gasification temperatures: (a) relationship 440 between carbon conversion rate and reaction time; (b) relationship between gasification reaction rate and carbon conversion rate

Using the reactivity index $R_{\mathrm{s}}$ (Eq.3) to quantify the char reactivity in isothermal gasification.

443 As shown in Fig. 7, the highest char reactivity of $0.099 \mathrm{~min}^{-1}$ was achieved with the MC600 at $4441000{ }^{\circ} \mathrm{C}$. While the reactivity reduced to the lowest of $0.011 \mathrm{~min}^{-1}$ was achieved with the MC1000 445 at $800{ }^{\circ} \mathrm{C}$. The char gasification reactivity index $R_{\mathrm{s}}$ increased with gasification temperature rising 446 and decreased with char production temperature rising. The $R_{\mathrm{S}}$ values of three kinds of chars 447 (MC600, MC800 and MC1000) at the gasification temperature of $1000{ }^{\circ} \mathrm{C}$ were 4.2, 5.8 and 6.7 448 times at $800{ }^{\circ} \mathrm{C}$, respectively. Under 800,900 and $1000{ }^{\circ} \mathrm{C}$ gasification temperatures, the $R_{\mathrm{s}}$ values 449 of MC600 were 2.2, 1.2 and 1.4 times that of MC1000, respectively. It can be inferred that the 450 gasification temperature had a much greater impact than the char production temperature. When the 451 carbon conversion rate was lower than $50 \%$, the reactivity of char increased was dominated by the 452 change of specific surface area. While the carbon conversion rate exceeded $50 \%$, the reactivity 453 rapid increase was because the metal oxides in the char ash had a certain catalytic effect on the 454 gasification reaction to promote the char gasification reaction. 


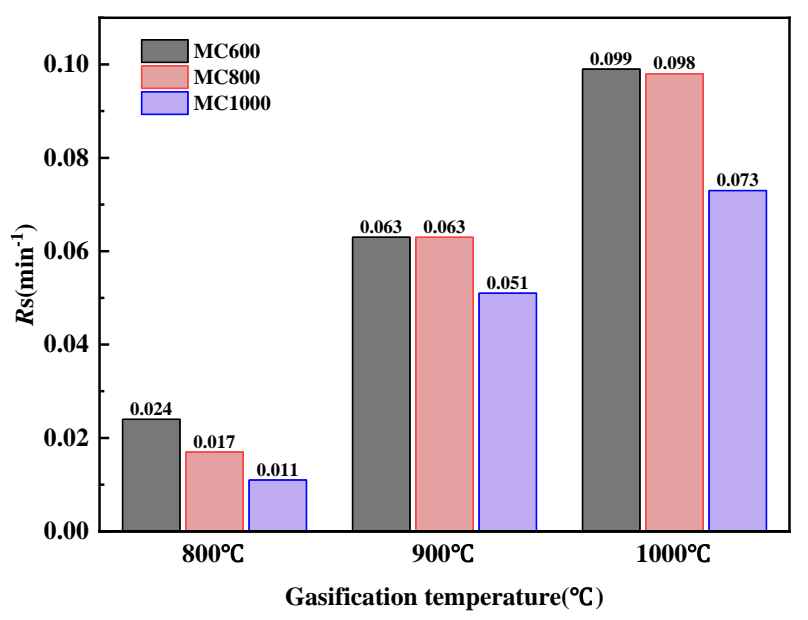

Fig. 7 Isothermal gasification reaction index $R$ s of different $\mathrm{MC}$ samples

\subsubsection{Kinetic analysis}

Three different kinetic models, i.e. RMP (Eq.6) SCM (Eq.7) and HM (Eq.8), were employed to analyze the experimental data of isothermal steam gasification of char. As shown in Table 4, the calculated kinetic parameters $E$ and $A$ of the three models all increased with the increase of char production temperature. A high activation energy value indicates that the gasification reaction is more difficult to proceed and this observation is consistent with the conclusion of XRD analysis. The values of activation energy calculated by the three models are consistent with the sequence of gasification activity of char. The consistency of the $E$ value of the char gasification reaction with the $A$ indicates a kinetic compensation effect: $\ln A=a E+b$. As shown in Fig 8, there is an excellent linear relationship between $A$ and $E$ values calculated by the three models, and the correlation coefficient values were all greater than 0.99 , which indicates an excellent dynamic compensation effect in the steam gasification of char. According to K. Yip et al. [52], the selective oxidation of carbon materials with heterogeneous carbon structures was the key factor determining the kinetic compensation effect. 


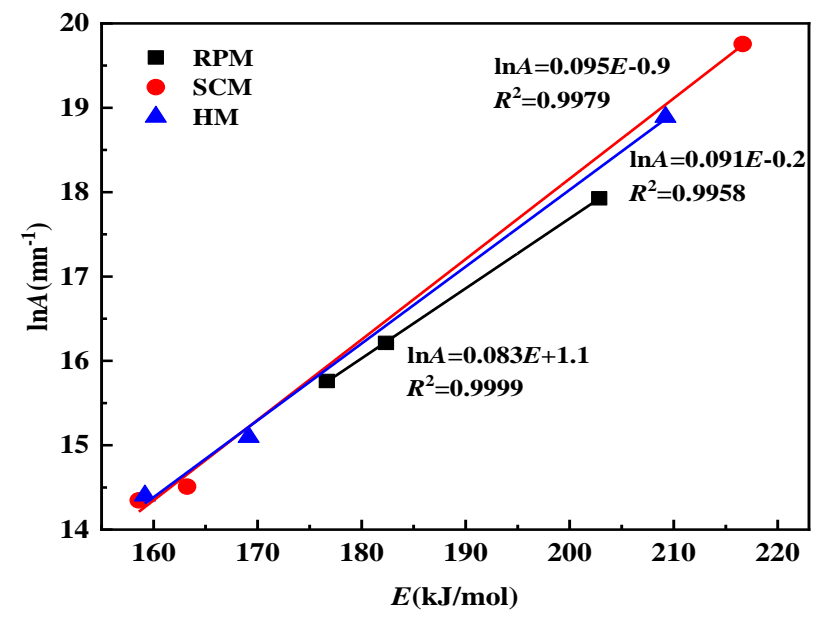

Fig.8 $A$ and $E$ dynamic compensation of three models considered to be the most accurate model to describe the gasification kinetics of MC samples. Compared with the other two models, the RPM model can not only described the phenomenon of the maximum reaction rate during the gasification, but also include the change of the gas-solid phase reaction interface with consideration of char development and collapse of micropores during the gasification reaction. The calculated $E$ for miscanthus char steam gasification was in the range from 176 to $203 \mathrm{~kJ} / \mathrm{mol}$, which was in line with the general results reviewed by Di Blasi, being143-237 kJ/mol with most of the results around 180-200 kJ/mol [53]. When the char production temperature was increased from $800{ }^{\circ} \mathrm{C}$ to $1000{ }^{\circ} \mathrm{C}$, the $E$ increased by $20.5 \mathrm{~kJ} / \mathrm{mol}$. This is about 4 times higher than the increase of the $E$ value when the char production temperature was increased from $600{ }^{\circ} \mathrm{C}$ to $800{ }^{\circ} \mathrm{C}$. This indicates that the char prepared at high temperature was more temperature resistance and more difficult to be gasified. Since high char production temperature consumes more energy and results in char product with low yield and poor reactivity, moderate char production temperature may favor desired char property in the real industrial application. 
Table 4 Calculated kinetic parameters of MC samples

\begin{tabular}{cccccccccc}
\hline & \multicolumn{3}{c}{$\mathrm{RPM}$} & \multicolumn{3}{c}{$\mathrm{SCM}$} & \multicolumn{3}{c}{$\mathrm{HM}$} \\
\cline { 2 - 9 } Samples & $E(\mathrm{~kJ} / \mathrm{mol})$ & $A\left(\mathrm{~min}^{-1}\right)$ & $R^{2}$ & $E(\mathrm{~kJ} / \mathrm{mol})$ & $A\left(\mathrm{~min}^{-1)}\right.$ & $R^{2}$ & $E(\mathrm{~kJ} / \mathrm{mol})$ & $A\left(\mathrm{~min}^{-1)}\right.$ & $R^{2}$ \\
\hline MC600 & 176.66 & $7.0 \mathrm{E}+6$ & 0.9986 & 158.58 & $1.7 \mathrm{E}+6$ & 0.9752 & 159.16 & $1.8 \mathrm{E}+6$ & 0.9681 \\
MC800 & 182.34 & $1.1 \mathrm{E}+7$ & 0.9999 & 163.23 & $2.0 \mathrm{E}+6$ & 0.9609 & 169.14 & $.3 .6 \mathrm{E}+6$ & 0.9592 \\
MC1000 & 202.84 & $6.1 \mathrm{E}+7$ & 0.9983 & 216.63 & $3.8 \mathrm{E}+8$ & 0.9869 & 209.21 & $1.6 \mathrm{E}+8$ & 0.9755 \\
\hline
\end{tabular}

489

490

491

\subsection{Non-isothermal gasification reactivity analysis}

\subsubsection{Effect of heating rate}

According to the results from char characterization and the isothermal gasification experiments, it can be concluded that the MC600 sample had the highest gasification reactivity when it was gasified at $1000{ }^{\circ} \mathrm{C}$. Therefore, MC600 was selected for the non-isothermal gasification experiments at $1000{ }^{\circ} \mathrm{C}$ to investigate the effect of the gasification heating rates on the char gasification. The TG and DTG curves of the MC600 gasification at different heating rates are shown in Fig. 9a and their initial gasification temperature $T_{\mathrm{i}}$, the peak temperature $T_{\mathrm{m}}$, and the final temperature $T_{\mathrm{f}}$ are given in Table 5. The TG curves of the gasification at different heating rates has the same trend with three stages. In the first stage (from room temperature to $T_{\mathrm{i}}$ ), the char remained unreacted. During the second (reaction) stage, the char was gasified with steam, where the solid carbon was continuously consumed until reached the $T_{\mathrm{m}}$. The final stage marked the end of gasification process. The DTG results show that the high heating rate resulted in the main reaction interval and the temperature for the peak weigh loss shifting to the high-temperature side and the values of $T_{\mathrm{i}}, T_{\mathrm{m}}$ and $T_{\mathrm{f}}$ increased. Meanwhile, it can be seen that with the increase of heating rate, the $S$ (Eq.4) grew gradually and the $t_{\mathrm{g}}$ was shortened, which indicates that higher heating rate could improve the gasification reactivity. 
rate of char. It can be found that high heating rate resulted in the curves of carbon conversion tate
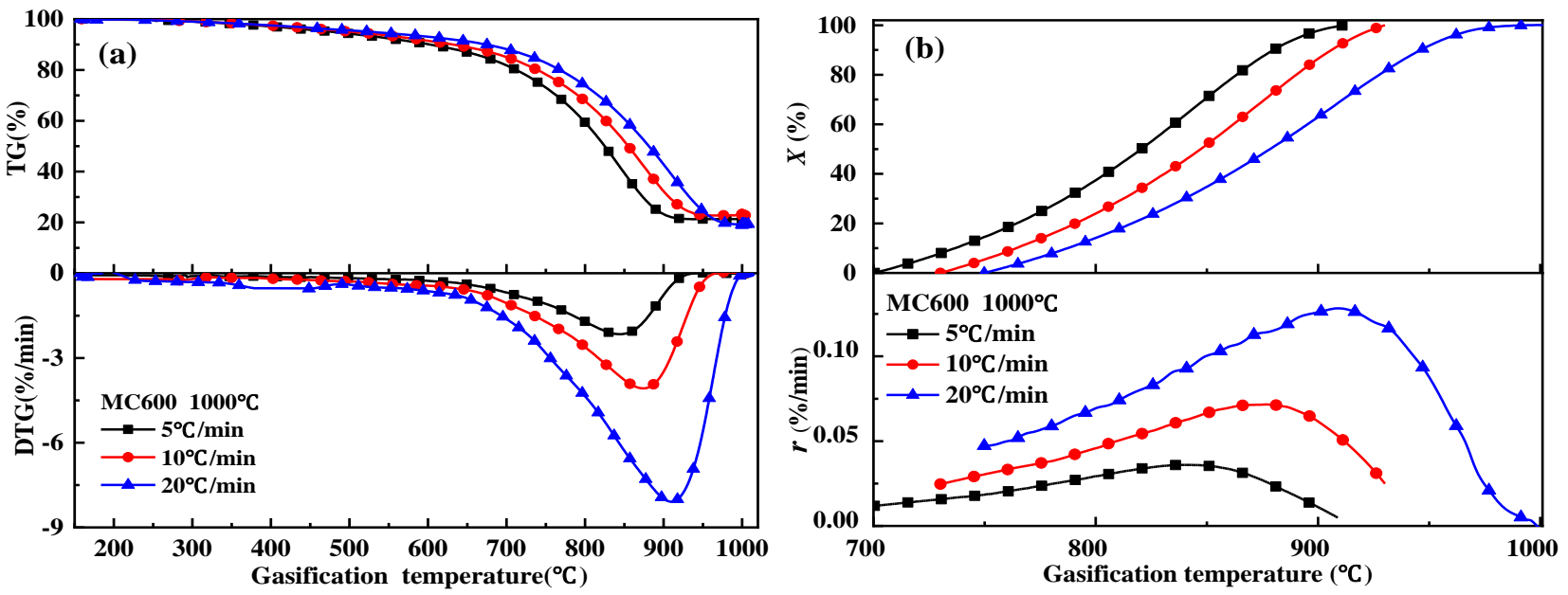

Fig. Non-isothermal gasification of char with different heating rates: (a) TG and DTG curves; (b) carbon conversion and gasification rate curves

Table 5 Characteristic parameters of non-isothermal gasification of char

\begin{tabular}{cccccccc}
\hline$\beta$ & $T_{\mathrm{i}}$ & $T_{\mathrm{m}}$ & $T_{\mathrm{f}}$ & $(\mathrm{d} X / \mathrm{dt})_{\max }$ & $(\mathrm{d} X / \mathrm{dt})_{\operatorname{mean}}$ & $t_{g}$ & $S$ \\
$\left({ }^{\circ} \mathrm{C} / \mathrm{min}\right)$ & $\left({ }^{\circ} \mathrm{C}\right)$ & $\left({ }^{\circ} \mathrm{C}\right)$ & $\left({ }^{\circ} \mathrm{C}\right)$ & $(\% / \mathrm{min})$ & $(\% / \mathrm{min})$ & $(\mathrm{min})$ & \\
\hline 5 & 700 & 844 & 912 & 0.01181 & 0.00834 & 42.2 & $2.2 \mathrm{E}-13$ \\
10 & 730 & 879 & 930 & 0.02489 & 0.02478 & 19.9 & $1.3 \mathrm{E}-12$ \\
20 & 750 & 912 & 992 & 0.04727 & 0.02184 & 12.7 & $1.9 \mathrm{E}-12$ \\
\hline
\end{tabular}




\subsubsection{Non-isothermal gasification reaction kinetic studies of MC}

The FWO (Eq.10), KAS (Eq.11) and Starink (Eq.12) methods were used to analyze the

kinetics of steam gasification of char at different heating rates, and the calculated values of activation energy $E$ at the carbon conversion rate of $10-90 \%$ were analyzed. The results are shown in Fig. 10. It can be found that the changing trends of the fitting line obtained by FWO, KAS and Starink at different conversion rates were consistent, approximate parallel regression reflected that the $E$ value determined at different $X$ can be described by a one-step reaction mechanism or a unity

530 of multiple reaction mechanisms. The relative error ranges of the fitted straight line slopes of the 531 three methods were $0-3.49 \%, 0.11-5.76 \%$, and $0.14-4.23 \%$. When the relative error of the fit 532 straight line slope was less than $10 \%$, the $E$ value can be considered as an independent of $X$ [54].

533 Table 6 shows that the average values of $E$ obtained by the three methods during the char steam 534 gasification were $235.78,230.85$, and $229.91 \mathrm{~kJ} / \mathrm{mol}$, and the correlation coefficients $R^{2}$ of the 535 fitted curves were all higher than 0.97, indicates that the calculated $E$ value is accurate and reliable.

536 The average activation energy calculated by the FWO method were larger than those calculated by 537 the KAS and Starink method, but the average values of activation energy were highly close by KAS 538 and Starink method. The comparison confirms that the FWO method can be considered as the best 539 method to describe the steam gasification of char, as its $R^{2}$ value was the highest and its liner fitting 540 has lower variation than other two methods. The calculated $E$ value with higher accuracy can be 541 used in the master curve method to find the mechanism function $f(X)$. 

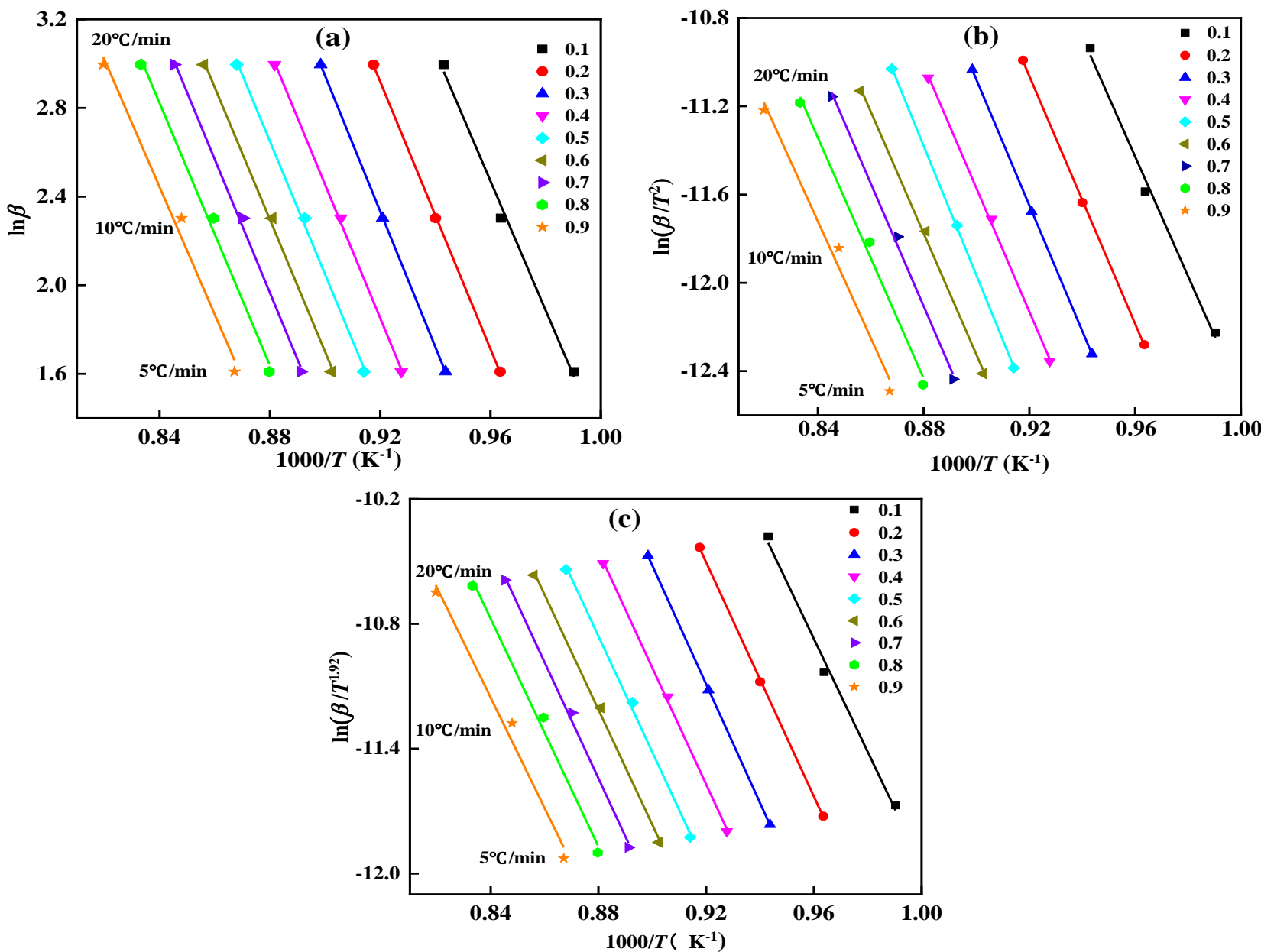

544 Fig.10 Kinetics fitting curves for non-isothermal gasification of MC samples: (a)FWO; (b) KAS; (c) Starink.

545 Table 6 Kinetic parameters Obtained from the non-isothermal gasification with different conversion rates

\begin{tabular}{|c|c|c|c|c|c|c|c|c|c|}
\hline \multirow{2}{*}{$X$} & \multicolumn{3}{|c|}{ FWO } & \multicolumn{3}{|c|}{ KAS } & \multicolumn{3}{|c|}{ Starink } \\
\hline & $E(\mathrm{~kJ} / \mathrm{mol})$ & $R^{2}$ & Slope & $E(\mathrm{~kJ} / \mathrm{mol})$ & $R^{2}$ & Slope & $E(\mathrm{~kJ} / \mathrm{mol})$ & $R^{2}$ & Slope \\
\hline 0.1 & 230.46 & 0.9901 & -29.15 & 225.23 & 0.9886 & -27.09 & 225.71 & 0.9887 & -27.17 \\
\hline 0.2 & 238.60 & 0.9997 & -30.18 & 233.21 & 0.9997 & -28.05 & 233.69 & 0.9997 & -28.13 \\
\hline 0.3 & 242.08 & 0.9999 & -30.62 & 236.53 & 0.9999 & -28.45 & 237.01 & 0.9999 & -28.53 \\
\hline 0.4 & 238.29 & 0.9987 & -30.14 & 232.21 & 0.9984 & -27.93 & 232.69 & 0.9984 & -28.01 \\
\hline 0.5 & 237.26 & 0.9965 & -30.01 & 244.18 & 0.9996 & -29.37 & 231.36 & 0.9958 & -27.85 \\
\hline 0.6 & 235.76 & 0.9969 & -29.82 & 228.97 & 0.9962 & -27.54 & 229.53 & 0.9962 & -27.63 \\
\hline 0.7 & 237.97 & 0.9953 & -30.10 & 231.13 & 0.9943 & -27.80 & 231.69 & 0.9944 & -27.89 \\
\hline 0.8 & 234.02 & 0.9880 & -29.60 & 226.72 & 0.9857 & -27.27 & 227.29 & 0.9858 & -27.36 \\
\hline 0.9 & 227.54 & 0.9757 & -28.78 & 219.49 & 0.9709 & -26.40 & 220.14 & 0.9711 & -26.50 \\
\hline Average & 235.78 & 0.9934 & -29.82 & 230.85 & 0.9926 & -27.77 & 229.91 & 0.9922 & -27.67 \\
\hline
\end{tabular}




\subsubsection{Determination of mechanism function $f(X)$}

Using Eq. 14, the temperature integral of gasification of char was calculated as a function of the selected $X$ by the previously estimated activation energy $E$. After that, the experimental master plots of $P(U) / P\left(U_{0.5}\right)$ versus $X$ from the thermal data at distinct heating rates of 5,10 and $20{ }^{\circ} \mathrm{C} / \mathrm{min}$ can be calculated. Fig. 11a shows the theoretical curve corresponding to the 14 kinetic model

551 functions [55] and an experimental curve of gasification reaction of char at different heating rates.

552 When the carbon conversion rate was within the range of $10-90 \%$, the three experimental curves at 553 different heating rates nearly forms one single curve, indicating that the char steam gasification 554 reaction can be described by a single mechanism function. When the conversion rate $X$ was lower 555 than $50 \%$, the experimental curve was in a good agreement with $\mathrm{F}_{2}$; when the conversion rate $X$ was 556 higher than $50 \%$, the experimental curve was in a good agreement with $\mathrm{D}_{1}$. Therefore the 557 corresponding $G(X)=(1-X)^{-1}-1$ and $X^{2}$ can be obtained. Therefore, the mechanism functions of $\mathrm{F}_{2}$ 558 and $\mathrm{D}_{1}$ are applicable to determine the preexponential factor $A$ according to the Eqs. 13 and 14. By 559 performing a least-squares fit on $G(X) \sim(E P(U)) / \beta R$, the slope is the $A$. Finally, the $A$ and $f(X)$ for the 560 steam gasification of char at three different heating rates of 5,10 , and $20{ }^{\circ} \mathrm{C} / \mathrm{min}$ were given in 561 Table 7. To validate the results of the above kinetic analysis approach, the fit between experimental 562 data and theoretical calculating values was performed. Based on Eq. 13, the value of $X$ can be 563 calculated as a function of reaction temperature $T$ through using the kinetic parameters in Table 7.

564 As seen from Fig. 11b, the calculated line and experimental data were almost perfectly matched, 565 which indicated that the $E, A$ and $f(X)$ could provide important theoretical foundation for the study 566 of steam gasification process of MC. 

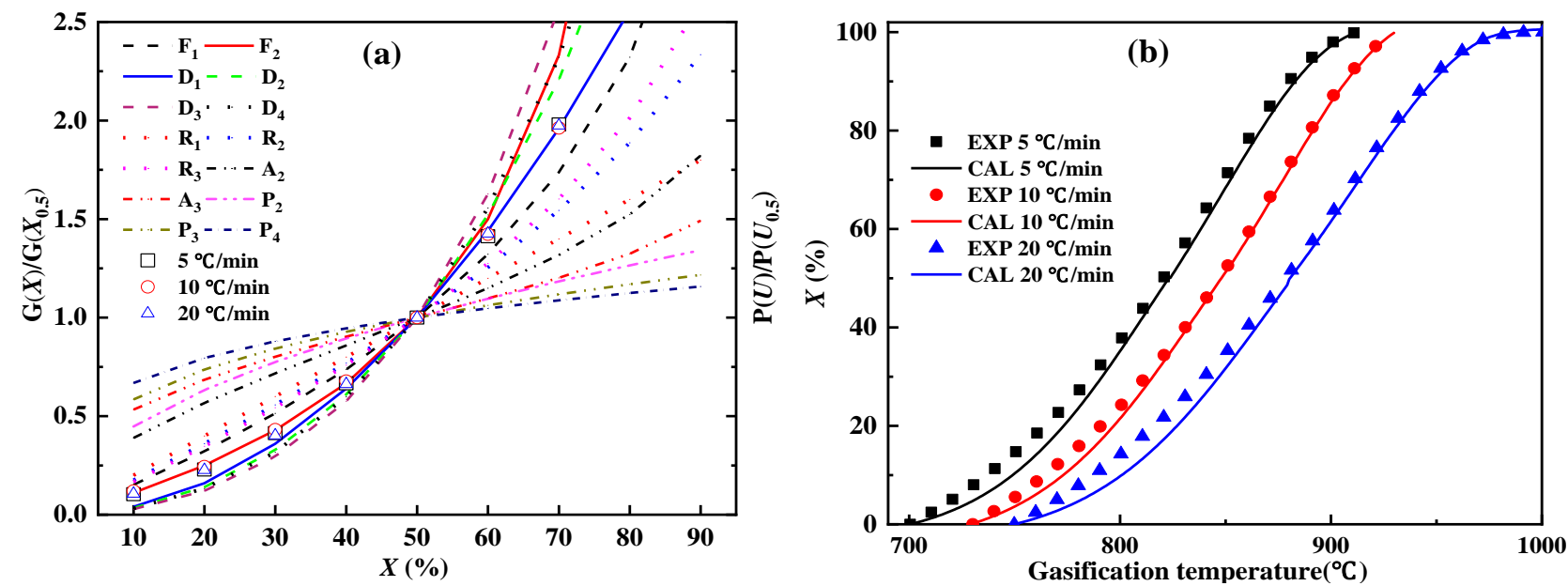

Fig.11 Determination of mechanism function MC samples: (a) $P(U) / P\left(U_{0.5}\right)$ versus $X$ from steam gasification of

MC at different heating rates and $G(X) / G\left(X_{0.5}\right)$ versus $X$ from various reaction models.(b) Comparison of calculated $X$ and experimental $X$ steam gasification of MCat different heating rates.

Table 7 Kinetic triplets of steam gasification of $\mathrm{MC}$ at 5,10 and $20^{\circ} \mathrm{C} / \mathrm{min}$

\begin{tabular}{cccccccccc}
\hline$G(X)$ & $\beta\left({ }^{\circ} \mathrm{C} / \mathrm{min}\right)$ & $A\left(\mathrm{~min}^{-1}\right)$ & $R^{2}$ & $f(X)$ & $G(X)$ & $\beta\left({ }^{\circ} \mathrm{C} / \mathrm{min}\right)$ & $A\left(\mathrm{~min}^{-1}\right)$ & $R^{2}$ & $f(X)$ \\
\hline & 5 & $1.17 \mathrm{E}+10$ & 0.9997 & & & 5 & $8.67 \mathrm{E}+9$ & 0.9806 & \\
$(1-X)^{-1}-1$ & 10 & $1.26 \mathrm{E}+10$ & 0.9996 & $(1-X)^{2}$ & $X^{2}$ & 10 & $1.01 \mathrm{E}+10$ & 0.9866 & $0.5 X$ \\
& 20 & $1.18 \mathrm{E}+10$ & 0.9992 & & & 20 & $8.17 \mathrm{E}+9$ & 0.9722 & \\
& & & & & & & & & \\
\end{tabular}

\section{CONCLUSIONS}

In this work, the microstructure features and steam gasification reactivity of MC obtained in different temperatures were investigated, and kinetic parameters were determined by different kinetic methods. The results showed that when the char production temperature increased, the surface structure of char was gradually destroyed and the specific surface area was increased in the char. The functional groups and on the char surface was gradual vanished, and microstructure of char was more orderly and regularized. The gasification reactivities of chars were mostly determined by the microcrystalline structure and the inherent alkali and alkaline earth metals. The gasification reactivity of MC prepared at low-temperature (i.e. $600{ }^{\circ} \mathrm{C}$ ) was relatively high. The 


\section{ACKNOWLEDGEMENT}

This work was supported by the Natural Science Foundation of China for Young Scholars (No.51706022), the Natural Science Foundation of Hunan Province of China for Young Scholars (No.2018JJ3545) and the Innovative Team of Key Technologies of Energy Conservation, Emission Reduction and Intelligent Control for Power-Generating Equipment and System at CSUST. The authors also would like to acknowledge the funding from EU Horizon 2020 Research and Innovation Program under the Marie Skłodowska-Curie Action (Grant Agreement No. 823745).

\section{REFERENCES}

[1] Yang Y,Brammer J G,Wright D G ,et al.Combined heat and power from the intermediate pyrolysis of biomass materials: performance, economics and environmental impact, Applied Energy 191 (2017) 639-652.

[2] Searle S Y,Malins C J.Will energy crop yields meet expectations? Biomass and Bioenergy 65 (2014) 3-12.

[3] Yan-Chong Y,Zi-Li Y,Gong-Ke Z.Research progress and comprehensive utilization of Miscanthus, Chinese Bulletin of Life Sciences 26(5) (2014) 474-480.

[4] Tian H,Jiao H,Cai J ,et al.Co-pyrolysis of Miscanthus Sacchariflorus and coals: A systematic study on the synergies in thermal decomposition, kinetics and vapour phase products, Fuel 262 (2020).

[5] Wang W-C,Lee A-C.Thermochemical Processing of Miscanthus through Fluidized-Bed Fast Pyrolysis: A Parametric Study, Chemical Engineering \& Technology 41(9) (2018) 1737-1745.

[6] Yorgun S.Fixed-Bed Pyrolysis ofMiscanthus x giganteus: Product Yields and Bio-Oil Characterization, Energy Sources 25(8) (2003) 779-790.

[7] Jayaraman K,Gökalp I.Pyrolysis, combustion and gasification characteristics of miscanthus and sewage sludge, Energy Conversion and Management 89 (2015) 83-91.

[8] Zhang J-1,Guo J,Wang G-w ,et al.Kinetics of petroleum coke/biomass blends during co-gasification, International Journal of Minerals, Metallurgy, and Materials 23(9) (2016) 1001-1010.

[9] Tong W,Liu Q,Ren S ,et al.Effect of pyrolysis temperature on pine sawdust chars and their gasification reactivity mechanism with $\mathrm{CO}_{2}$, Asia-Pacific Journal of Chemical Engineering 13(6) (2018).

[10] Detchusananard T,Sharma S,Maréchal F ,et al.Multi-objective optimization of sorption enhanced steam biomass gasification with solid oxide fuel cell, Energy Conversion and Management 182 (2019) 412-429.

[11] Sepe A M,Li J,Paul M C.Assessing biomass steam gasification technologies using a multi-purpose model, Energy Conversion and Management 129 (2016) 216-226.

[12] Škrbić B D,Đurišić-Mladenović N,Cvejanov J.Differentiation of syngases produced by steam gasification of mono- and 
mixed sources feedstock: A chemometric approach, Energy Conversion and Management 171 (2018) 1193-1201.

[13] Alnouss A,Mckay G,Al-Ansari T.A comparison of steam and oxygen fed biomass gasification through a techno-economic-environmental study, Energy Conversion and Management 208 (2020).

[14] Waheed Q M K,Wu C,Williams P T.Hydrogen production from high temperature steam catalytic gasification of bio-char, Journal of the Energy Institute 89(2) (2016) 222-230.

[15] Mermoud F,Salvador S,Vandesteene L ,et al.Influence of the pyrolysis heating rate on the steam gasification rate of large wood char particles, Fuel 85(10-11) (2006) 1473-1482.

[16] Ferreira S D,Lazzarotto I P,Junges J ,et al.Steam gasification of biochar derived from elephant grass pyrolysis in a screw reactor, Energy Conversion and Management 153 (2017) 163-174.

[17] Li R,Zhang J,Wang G, et al.Study on $\mathrm{CO}_{2}$ gasification reactivity of biomass char derived from high-temperature rapid pyrolysis, Applied Thermal Engineering 121 (2017) 1022-1031.

[18] Surup G R,Nielsen H K,Heidelmann M ,et al.Characterization and reactivity of charcoal from high temperature pyrolysis $\left(800-1600{ }^{\circ} \mathrm{C}\right)$, Fuel 235 (2019) 1544-1554.

[19] Zhang J,Liu J,Liu R.Effects of pyrolysis temperature and heating time on biochar obtained from the pyrolysis of straw and lignosulfonate, Bioresour Technol 176 (2015) 288-291.

[20] Guizani C,Jeguirim M,Gadiou R , et al.Biomass char gasification by $\mathrm{H}_{2} \mathrm{O}, \mathrm{CO}_{2}$ and their mixture: Evolution of chemical, textural and structural properties of the chars, Energy 112 (2016) 133-145.

[21] Lopez G,Alvarez J,Amutio M ,et al.Assessment of steam gasification kinetics of the char from lignocellulosic biomass in a conical spouted bed reactor, Energy 107 (2016) 493-501.

[22] Tong W,Liu Q,Yang $\mathrm{C}$,et al.Effect of pore structure on $\mathrm{CO}_{2}$ gasification reactivity of biomass chars under high-temperature pyrolysis, Journal of the Energy Institute (2019).

[23] Diao R,Zhu X,Wang C , et al.Synergistic effect of physicochemical properties and reaction temperature on gasification reactivity of walnut shell chars, Energy Conversion and Management 204 (2020).

[24] Wang G,Zhang J,Chang W ,et al.Structural features and gasification reactivity of biomass chars pyrolyzed in different atmospheres at high temperature, Energy 147 (2018) 25-35.

[25] Gómez-Barea A,Ollero P.An approximate method for solving gas-solid non-catalytic reactions, Chemical Engineering Science 61(11) (2006) 3725-3735.

[26] Le C D,Kolaczkowski S T.Steam gasification of a refuse derived char: Reactivity and kinetics, Chemical Engineering Research and Design 102 (2015) 389-398.

[27] Fan Y,Yu Z,Fang S ,et al.Investigation on the co-combustion of oil shale and municipal solid waste by using thermogravimetric analysis, Energy Conversion and Management 117 (2016) 367-374.

[28] Tahmasebi A,Kassim M A,Yu J ,et al.Thermogravimetric study of the combustion of Tetraselmis suecica microalgae and its blend with a Victorian brown coal in O2/N2 and O2/CO2 atmospheres, Bioresour Technol 150 (2013) 15-27.

[29] Azargohar R,Nanda S,Kozinski J A ,et al.Effects of temperature on the physicochemical characteristics of fast pyrolysis bio-chars derived from Canadian waste biomass, Fuel 125 (2014) 90-100.

[30] Ahmed I I,Gupta A K.Kinetics of woodchips char gasification with steam and carbon dioxide, Applied Energy 88(5) (2011) 1613-1619.

[31] Zhai M,Zhang Y,Dong P ,et al.Characteristics of rice husk char gasification with steam, Fuel 158 (2015) 42-49.

[32] Özsin G,Pütün A E.TGA/MS/FT-IR study for kinetic evaluation and evolved gas analysis of a biomass/PVC co-pyrolysis process, Energy Conversion and Management 182 (2019) 143-153.

[33] Özsin G,Pütün A E.Insights into pyrolysis and co-pyrolysis of biomass and polystyrene: Thermochemical behaviors, kinetics and evolved gas analysis, Energy Conversion and Management 149 (2017) 675-685.

[34] Chen J,Wang Y,Lang X ,et al.Evaluation of agricultural residues pyrolysis under non-isothermal conditions: Thermal behaviors, kinetics, and thermodynamics, Bioresource Technology 241 (2017) 340-348. 
[35] Cetin E,Moghtaderi B,Gupta R ,et al.Influence of pyrolysis conditions on the structure and gasification reactivity of biomass chars, Fuel 83(16) (2004) 2139-2150.

[36] Zhai M,Liu J,Wang Z ,et al.Gasification characteristics of sawdust char at a high-temperature steam atmosphere, Energy 128 (2017) 509-518.

[37] Meng F,Yu J,Tahmasebi A, et al.Characteristics of Chars from Low-Temperature Pyrolysis of Lignite, Energy \& Fuels 28(1) (2013) 275-284.

[38] Pütün E,Pütün A E,Kırbıyık Ç.Comparative studies on adsorptive removal of heavy metal ions by biosorbent, bio-char and activated carbon obtained from low cost agro-residue, Water Science and Technology 73(2) (2016) 423-436.

[39] Lin X,Wang C,Ideta $\mathrm{K}$, et al.Insights into the functional group transformation of a chinese brown coal during slow pyrolysis by combining various experiments, Fuel 118 (2014) 257-264.

[40] Zeng Z W,Tan X F,Liu Y G , et al.Comprehensive Adsorption Studies of Doxycycline and Ciprofloxacin Antibiotics by Biochars Prepared at Different Temperatures, Front Chem 6 (2018) 80.

[41] Chutia R S,Kataki R,Bhaskar T.Characterization of liquid and solid product from pyrolysis of Pongamia glabra deoiled cake, Bioresour Technol 165 (2014) 336-342.

[42] Deng L,Ye J,Jin X, et al.Transformation and release of potassium during fixed-bed pyrolysis of biomass, Journal of the Energy Institute 91(4) (2018) 630-637.

[43] Jensen P A,Frandsen F J,Dam-Johansen K ,et al.Experimental Investigation of the Transformation and Release to Gas Phase of Potassium and Chlorine during Straw Pyrolysis, Energy \& Fuels 14(6) (2000) 1280-1285.

[44] Zhao H-b,Song Q,Wu X-y ,et al.Study on the Transformation of Inherent Potassium during the Fast-Pyrolysis Process of Rice Straw, Energy \& Fuels 29(10) (2015) 6404-6411.

[45] Zhao Y,Feng D,Zhang Y, et al.Effect of pyrolysis temperature on char structure and chemical speciation of alkali and alkaline earth metallic species in biochar, Fuel Processing Technology 141 (2016) 54-60.

[46] Cui Z,Fu P,Li N ,et al.The mineral conversion and ash fusion characteristics of cornstraw, Journal of Shangdong University of Technology (5) (2018) 7-10.

[47] Okuno T,Sonoyama N,Hayashi J-i ,et al.Primary Release of Alkali and Alkaline Earth Metallic Species during the Pyrolysis of Pulverized Biomass, Energy \& Fuels 19(5) (2005) 2164-2171.

[48] Mitsuoka K,Hayashi S,Amano H ,et al.Gasification of woody biomass char with CO2: The catalytic effects of K and Ca species on char gasification reactivity, Fuel Processing Technology 92(1) (2011) 26-31.

[49] Feng D,Zhao Y,Zhang Y ,et al.Changes of biochar physiochemical structures during tar $\mathrm{H} 2 \mathrm{O}$ and CO 2 heterogeneous reforming with biochar, Fuel Processing Technology 165 (2017) 72-79.

[50] Zhao Y,Feng D,Zhang Y ,et al.Migration of Alkali and Alkaline Earth Metallic Species and Structure Analysis of Sawdust Pyrolysis Biochar, Korean Chemical Engineering Research 54(5) (2016) 659-664.

[51] Perander M,Demartini N,Brink A, et al.Catalytic effect of $\mathrm{Ca}$ and $\mathrm{K}_{\text {on }} \mathrm{CO}_{2}$ gasification of spruce wood char, Fuel 150 (2015) 464-472.

[52] Yip K,Ng E,Li C-Z ,et al.A mechanistic study on kinetic compensation effect during low-temperature oxidation of coal chars, Proceedings of the Combustion Institute 33(2) (2011) 1755-1762.

[53] Di Blasi C.Combustion and gasification rates of lignocellulosic chars, Progress in Energy and Combustion Science 35(2) (2009) 121-140.

[54] Chen J,Wang Y,Lang X ,et al.Evaluation of agricultural residues pyrolysis under non-isothermal conditions: Thermal behaviors, kinetics, and thermodynamics, Bioresour Technol 241 (2017) 340-348.

[55] Chen C,Lu Z,Ma X ,et al.Oxy-fuel combustion characteristics and kinetics of microalgae Chlorella vulgaris by thermogravimetric analysis, Bioresour Technol 144 (2013) 563-571. 